\title{
O ENSINO DE CIÊNCIAS E A INCLUSÃO DO TEMA HANSENÍASE NAS ESCOLAS
}

\author{
Ivonete Alves de Lima Cavaliere ${ }^{1}$ \\ Danielle Grynszpan ${ }^{2}$
}

\section{RESUMO}

Este artigo reúne dados e reflexões que são fruto de uma pesquisa de cunho qualitativo, desenvolvida em quatro escolas localizadas nas imediações do Hospital Estadual Tavares Macedo (HETM), no município de Itaboraí, interior do Estado do Rio de Janeiro. Buscamos conhecer e entender os significados das principais ideias, conhecimentos e crenças sobre hanseníase desta comunidade escolar do entorno do HETM, antigo Hospital-Colônia onde se internavam os doentes. Além disso, procuramos estudar se e como o tema era abordado no desenvolvimento do trabalho educativo nestes estabelecimentos de ensino, uma vez que neles estudam ou mesmo trabalham indivíduos cujas famílias abrigam portadores ou ex-portadores da doença. O procedimento metodológico envolveu um levantamento histórico do HETM, a busca de informações sobre seu funcionamento em diversos períodos desde sua implantação em Itaboraí, uma análise documental, bem como a realização de entrevistas individuais semi-estruturadas e observações de campo. Levamos em conta as dimensões cognitiva e afetiva, além das interações sociais entre os diferentes atores, com o objetivo de que este trabalho possa contribuir para o debate sobre o enfrentamento de uma questão de saúde local a partir do ensino.

Palavras-Chave: educação formal, ensino de ciências, saúde, hanseníase

\section{ABSTRACT}

This article presents data and reflections derived from a qualitative research work developed in four sschools located close to the Tavares Macedo State Hospital (HETM - Hospital Estadual Tavares Macedo), in the municipality of Itaboraí, interior of the State of Rio de Janeiro. We have tried to identify and Understand the meaning of the main ideas, knowledge and beliefs that the school community has about the HETM, a former Hospital-Colony where patients used to be hospitalized. In addition, we've tried to know if and how the topic is approached in the educational work in these schools, taking into account the fact that there are carriers or former carriers of the disease among school students and staff. The methodological procedure involved a historical survey at the HETM, in search for information about its operation in different periods of time since its beginning in Itaboraí. Document analysis as well as semi-structured interviews with individuals and field observations were carried out. We have considered cognitive and affective dimensions, as well as social interactions among other factors with the purpose of contributing for a debate about how to face an issue of local health having education as a starting point.

Key-words: formal education, science teaching, health, Hansen's disease

\section{INTRODUÇÃO}

Este artigo é o resultado de uma pesquisa de mestrado apresentada ao Instituto Oswaldo Cruz da Fundação Oswaldo Cruz FIOCRUZ, intitulada FÁBRICA DE IMAGINÁRIO, USINA DE ESTIGMA: CONHECIMENTOS, VISÕES E CRENÇAS DE UMA COMUNIDADE ESCOLAR SOBRE A HANSENÍASE, que foi desenvolvida em quatro escolas do município de Itaboraí e pretendeu conhecer o entendimento, as ideias e as crenças que a comunidade escolar do entorno do Hospital Estadual Tavares Macedo (HETM) tem sobre hanseníase.

A hanseníase é uma doença infectocontagiosa, causada por uma bactéria denominada Mycobacterium leprae, descrita, em 1874, pelo médico norueguês Gerhard HenrikArmauer Hansen.

A doença foi totalmente erradicada nos 
países desenvolvidos (Europa central e Escandinávia), mas, em nosso país, continua apresentando uma tendência crescente em decorrência das condições sociais e econômicas. $\mathrm{O}$ Brasil é, atualmente, o primeiro país do mundo em prevalência (número de indivíduos doentes em cada 10.000 habitantes) da doença, que é de 4,52 casos e o segundo em número absoluto de casos (79.908 casos em registro ativo).

A enfermidade é amplamente distribuída no hemisfério sul, estando presente em quase todos os países da África, da América latina e da Ásia. No entanto, atualmente, nove países são considerados endêmicos e apresentam prevalência acima de 1 por 10.000 habitantes.

O Brasil continua a integrar a lista dos países com maior magnitude da doença que afeta indistintamente ambos os sexos, sendo a faixa etária mais acometida a do adulto jovem. O período de incubação é longo, em média de 3 a 10 anos. Por isso, quando uma criança adoece significa que teve contato ainda muito pequena com doente sem tratamento. Nos últimos cinco anos, tem-se uma média de 40.000 casos detectados/ano, com $8 \%$ em menores de 15 anos e 3.000 com deformidades físicas instaladas. Apesar de o diagnóstico ser essencialmente clínico, baseado no exame da pele, dos nervos periféricos e na história epidemiológica, percebe-se que, embora seja simples, ainda há demora no seu estabelecimento. Torna-se imprescindível desenvolver um trabalho em escolas localizadas no entorno de um Hospital que foi Colônia de "Leprosos".

A pesquisa teve por objetivo estudar as visões da comunidade escolar do entorno do Hospital Estadual Tavares Macedo (HETM), antigo Hospital-Colônia, onde eram internados os indivíduos que contraíam "lepra", hoje denominada hanseníase. Entende-se por visões, neste trabalho, as ideias, conhecimentos, concepções e crenças da comunidade escolar, formada por docentes e discentes, sobre hanseníase. As quatro escolas foram selecionadas para o estudo porque atendem à demanda da comunidade do entorno do HETM, formada pela população local (moradores da região) e pelos pacientes e seus familiares (7.000 moradores).

Os procedimentos metodológicos foram iniciados com um levantamento do material bibliográfico referente ao tema hanseníase, incluindo-se aí, também, elementos relativos aos aspectos históricos e culturais da comunidade.

Reunimos, ainda, dados documentais sobre o HETM. Portanto, o estudo do contexto constou de levantamento documental, levantamento da história do HETM e das características das escolas, além de um levantamento teórico sobre o preconceito e o estigma

Com base no estudo do contexto, em observação de campo e interação entre os atores sociais e a comunidade local, foi elaborado o roteiro de entrevista. Em seguida, escolhemos, na comunidade escolar, educadores e educandos para serem entrevistados. Os professores foram sondados a partir de dois parâmetros que nos pareceram chave: maior carga horária, que possibilita um maior tempo de contato com os alunos, e por serem os responsáveis pela abordagem do tema saúde na escola. Os alunos foram selecionados por seu papel de representantes de turma, bem como pela idade acima de 12 anos. Como critério de inclusão de ambos, houve a assinatura do "Termo de Consentimento Livre e Esclarecido", concordando em participar da pesquisa.

Optou-se por utilizar entrevistas. Estas se preocupam, nas Ciências Sociais, com um nível de realidade que não pode ser quantificado, pois trabalham com motivos, aspirações, crenças, valores e atitudes. A abordagem qualitativa aprofunda-se no mundo dos significados das ações e relações humanas (MINAYO, 1994). As entrevistas foram conduzidas pela autora da pesquisa e realizadas nas dependências de cada escola, obedecendo ao critério de resguardar a privacidade dos entrevistandos. Foram áudio-gravadas, devido ao fato de a gravação ter a vantagem de registrar todas as expressões orais imediatamente, deixando o entrevistador livre para dedicar toda atenção ao entrevistado (LÜDKE, 1986).

\section{RESULTADOS E DISCUSSÃO}

Após levantamento e análise de dados, obtiveram-se os seguintes resultados: no levantamento do material bibliográfico, aspectos históricos e culturais da comunidade; revisão bibliográfica sobre a hanseníase. Em Itaboraí, foram encontradas três monografias sobre o Hospital e livros que abordam este tema na biblioteca do próprio hospital, bem como documentos e fotografias, registros importantes para a composição da história da criação da Colônia ou HETM, que, atualmente, é asilo e faz internações de pacientes 
com recidiva, além de dispor de um ambulatório com especialidades médicas.

A pesquisa foi realizada com um total de 53 entrevistados, sendo 22 educandos e 31 educadores vinculados a uma das quatro escolas, que foram identificadas como Escolas "A", "B", "C" e "D”, de acordo com a ordem de realização das entrevistas. Foram realizadas 17 entrevistas na escola " $A$ ", seis na escola "B", 22 na escola "C" e 08 na escola "D".

A grande maioria dos educadores pertencia ao sexo feminino, perfazendo $99 \%$ da amostra, com idade de 24 a 69 anos. Quanto aos estudantes, $77 \%$ do sexo Feminino, com idade de 12 a 62 anos (contando alunos do Curso de Educação para Jovens e Adultos EJA).

$\mathrm{Na}$ escola "A", foram entrevistadas dez educadoras, incluindo diretora, orientadora e professoras, com idade entre 38 e 69 anos e com tempo de serviço de 10 a 36 anos, sendo que $90 \%$ com mais de 25 anos de trabalho nesta escola. Foram também entrevistados sete estudantes com idades de 12 a 16 anos, todos alunos de $5^{\mathrm{a}}$ a $8^{\mathrm{a}}$ séries do Ensino Fundamental, selecionados por serem representantes de turma.

$\mathrm{Na}$ escola "B", foram realizadas seis entrevistas, sendo duas com educadores com idade de 49 a 78 anos e quatro com educandos, com idades de 30 a 62 anos, que trabalham na escola há mais de 30 anos.

Na escola "C", foram realizadas vinte e duas entrevistas, sendo 11 com educadores com idades de 27 a 58 anos, aproximadamente 90\% deles trabalham nesta escola há mais de dez anos, e 11 educandos, com idades de 15 a 55 anos.

$\mathrm{Na}$ escola "D", foram entrevistadas oito educadoras com idades de 26 a 62 anos e com tempo de serviço de 3 a 21 anos.

Foram utilizadas as contribuições da obra de Bourdieu, com os conceitos de campo e de habitus em nossa análise e interpretação dos dados, e Goffman, na análise das consequências psicossociais relatadas nas entrevistas.

\section{O ENTENDIMENTO DE EDUCADORES E EDUCANDOS SOBRE A DOENÇA}

\section{HANSENÍASE}

1) Quanto a CONCEITO DE

Na escola "A": é doença hereditária, que pega por falta de higiene ou por ferida aberta. A transmissão ocorre pela transfusão de sangue e drogas injetáveis. Na escola "B": é doença hereditária e transmissível através do contato pela pele. Na escola "C": é doença hereditária e contagiosa, pegando pela roupa. Na escola " $D$ ": é doença hereditária, que mutila, além de ser contagiosa; também é doença dos nervos. Predominando o conceito que a hanseníase é doença hereditária.

\section{2) Quanto ao TRATAMENTO DA HANSENÍASE}

Sabe-se que na escola "A": não se conhece o tratamento, mas ele existe; uma parte acha que o tratamento é oferecido no pavilhão, outra parte não tem conhecimento. Na escola "B": não se conhece o tratamento, nem a medicação, mas é sabido que são oferecidos no posto de saúde. Na escola "C": não se conhece o tratamento; sabe-se que o tratamento é oferecido no posto de saúde e no HETM. Na escola "D": predominou o desconhecimento, embora tenha sido assinalada a importância do tratamento.

\section{3) Quanto à EXISTÊNCIA DE CURA}

$\mathrm{Na}$ escola "A": só se for no "começo" do desenvolvimento da doença. Na escola "B": não tem cura, mas tem controle (por medicamento). $\mathrm{Na}$ escola "C": só se for no "começo" do desenvolvimento da doença. $\mathrm{Na}$ escola " $\mathrm{D}$ ": o tratamento é eficaz e a cura só ocorre se a doença estiver no começo. Predominou a ideia de que a cura é possível apenas no início do desenvolvimento da doença.

\section{4) Quanto a COMO SE DÁ A} TRANSMISSÃO DAHANSENÍASE

$\mathrm{Na}$ escola "A": é hereditária, e existe contágio pela pele, por uso do mesmo vaso sanitário ou por contato sexual. $\mathrm{Na}$ escola "B": não se conhece como "pega", mas faz-se associação à falta de resistência. Na escola " $C$ ": não se conhece como "pega", mas supõe-se que seja hereditário e também através de contágio pela roupa. $\mathrm{Na}$ escola " $\mathrm{D}$ ": contágio por corte na pele ou por meio do ar. O desconhecimento prevalece, inclusive com a manutenção de idéias sobre contágio em vez de transmissão.

\section{5) Quanto ao CONHECIMENTO SOBREA HANSENÍASE}

$\mathrm{Na}$ escola "A": por meio de folhetos ou no convívio na Colônia. Na escola "B": por meio das 
pessoas da Colônia, além da mídia televisiva. $\mathrm{Na}$ escola "C": por meio de folhetos distribuídos no hospital municipal ou amigos da Colônia. Na escola "D": por meio das pessoas na convivência na Colônia ou a minoria por meio de leitura de livros. Predominou obtenção do conhecimento através da convivência entre habitantes do HETM.

6) Quanto à EXISTÊNCIA DE PRECONCEITO CONTRA O PORTADOR DE HANSENÍASE

$\mathrm{Na}$ escola "A": existe medo de "pegar"; "leproso" é termo que ofende ou magoa. Na escola "B": dizem não haver (dissimulam) ou negam. $\mathrm{Na}$ escola "C": dizem faltar informação e que esta falta provocaria isolamento. $\mathrm{Na}$ escola " $\mathrm{D}$ ": existe preconceito, inclusive do próprio doente, que é chamado de "leproso", provocando mal-estar e posturas defensivas. Nas escolas, procura-se evitar o assunto por medo do preconceito e estigma.

7) Quanto à ABORDAGEM SOBRE O TEMAHANSENÍASE NAS ESCOLAS

Nas quatro escolas, "A", "B", “C” e "D": o tema não foi abordado. As escolas não trabalham o tema hanseníase devido à dificuldade do enfrentamento.

\section{8) Quanto ao QUE GOSTARIA DE SABER SOBREAHANSENÍASE}

$\mathrm{Na}$ escola "A": informações sobre transmissão e tratamento. $\mathrm{Na}$ escola "B": informações sobre transmissão e tratamento. $\mathrm{Na}$ escola "C": informações sobre transmissão e tratamento, bem como sobre possibilidade de cura. $\mathrm{Na}$ escola "D": informações sobre a transmissão e tratamento. A maioria indica que deseja e tem necessidade de maiores informações sobre a doença.

Obtivemos um material diverso e heterogêneo sobre a hanseníase, com relatos bastante ilustrativos. Este trabalho pretendeu oferecer esclarecimentos sobre a relação entre ciência e sociedade, buscando explicar os motivos pelos quais se consolidou, ao longo do tempo, um aparente "desinteresse" pela aquisição de conhecimento sobre hanseníase. Ao ressaltar aspectos como a negação da existência de uma doença que ainda é endêmica na região, o que apareceu de forma explícita ou dissimulada, percebe-se que, na comunidade estudada, possuir conhecimento científico sobre a doença em questão poderia ser "comprometedor". Neste contexto, o interesse só poderia ser justificado pelo desejo de adquirir um "saber" específico, porque poderia comprometer o grupo, porque a atitude de se implicar denunciaria a existência de alguém da família ou o próprio "desejante do saber" ser portador da doença. A pretensão de conhecer melhor a hanseníase já poderia evidenciar uma suspeita de envolvimento e, talvez, seja esta uma das causas para explicar o constrangimento em buscar o aprendizado. Assim sendo, surge um impasse entre o desejo de adquirir conhecimento sobre a doença e o constrangimento em ser portador desse "saber". A possibilidade de aprender para ajudar na prevenção, ou para contribuir com a diminuição do estigma que recai sobre a doença, não parecia preponderar sobre a vontade de se abster ou o medo de se comprometer.

Vimos que os educadores só podiam acolher as questões que diziam respeito à hanseníase quando extrapolavam de sua individualidade para o coletivo, justificando seu desejo de aprender pela necessidade de ensinar ao aluno. Por outro lado, para que o professor pudesse promover a formação de seus alunos, seria necessário que ele não se ativesse à ideia de aprender para ensinar, mas que pudesse constituir um espaço de discussão, aberto àqueles que de fato viessem a se engajar nesse projeto de tornarem-se "conhecedores da hanseníase", fazendo a ponte entre a escola e a vida.

Vale ressaltar que os professores das quatro escolas possuíam um bom nível de escolaridade. $\mathrm{Na}$ escola "A", 83 \% possuíam curso superior. Na escola "B", 40\% possuíam curso superior. Na escola " $C$ ", $37 \%$ possuíam curso superior e na escola " $D$ ”, $100 \%$ possuíam curso superior. Apesar disso, constatamos que o nível de conhecimento dos educadores e educandos sobre hanseníase nas escolas estudadas foi baixo. Apenas um aluno, por ter sido portador da doença, apresentou uma ideia geral sobre o conceito da doença e sobre seu significado. E somente um professor se destacou, provavelmente também pela experiência própria, mesmo assim, demonstrou possuir um conhecimento defasado.

Um dado especialmente significativo foi que nenhum entrevistado, sendo educador ou educando, mencionou ter havido nem mesmo uma palestra sobre hanseníase em sua escola. Estas escolas foram selecionadas devido à proximidade com o HETM, justamente porque supúnhamos haver maior envolvimento relacionado à doença por parte dessa população e, no embate entre diferentes interesses, esperávamos que essa comunidade pudesse eleger a 
problemática local (hanseníase) como foco de seus interesses. Além disso, notamos que o espaço escolar parece não servir como um espaço de convívio que permite a abordagem de um tema delicado como o da hanseníase em nenhuma das quatro escolas.

Acreditamos que essa aparente falta de interesse pelas questões relacionadas à hanseníase pode significar medo de enfrentamento da doença, na medida em que tomar consciência das questões ligadas à transmissão, por exemplo, pode representar perdas importantes para as relações sociais. Portanto, o aparente "desinteresse" pode representar ainda a necessidade de efetiva ajuda das autoridades educacionais para a inserção da temática de maneira definitiva nas escolas, possibilitando o enfrentamento da hanseníase.

Os ex-portadores de hanseníase, professores e alunos, pareciam não demonstrar mais conhecimentos do que os demais, ou seja, seus conhecimentos, suas crenças e concepções foram semelhantes às dos outros. Este dado pode ser representativo de medo do enfrentamento da doença.

É importante destacar as considerações da Comissão Internacional sobre Educação para o século XXI, incorporadas nas determinações da Lei 9.394/96, que determina a construção dos currículos, nos Ensinos Fundamental e Médio, "com uma Base Nacional Comum, a ser complementada, em cada sistema de ensino e estabelecimento escolar, por uma parte diversificada, exigida pelas características regionais e locais da sociedade, da cultura, da economia e da clientela" (Art. 26).

Com os resultados deste trabalho, por meio das falas dos educadores, pode-se perceber no olhar dos agentes envolvidos o estigma deflagrado à doença hanseníase. Passando de um enfoque centrado nas "crendices" atribuídas geralmente à deficiência de informações, para a reflexão sobre abordagem, possibilidades e, principalmente sobre suas limitações. A proposta metodológica privilegiou as falas e as vivências. Tal prática valorizou a expressão das emoções e experiências individuais, estimulando o autoconhecimento. Nesse sentido, insere-se numa perspectiva de educação imbuída do propósito de oferecer sua parcela de contribuição para um mundo melhor. Assim, nossa pesquisa mostrou-se valiosa por suscitar o desejo da busca do conhecimento, a partir da reflexão crítica sobre a importância do seu papel naquela escola em especial e na sociedade em geral, no que se refere ao ensino de ciências hanseníase.

\section{COMO FALAR DE HANSENÍASE NA SALA DE AULA?}

Como podem ser introduzidas no ensino de Ciências as questões relacionadas à hanseníase? E como o ensino de Ciências pode ser a favor da educação em saúde e contra o preconceito? Entendemos que os resultados da pesquisa realizada nas escolas do entorno do Hospital Colônia demonstram a fragilidade dos conhecimentos adquiridos pelas pessoas que compõem a escola, possibilitando, assim, uma introdução ao tema. Os dados coletados na pesquisa apontam para a importância de se desenvolver um trabalho efetivo de educação em saúde nestas escolas. Há, no Programa de Saúde, que costuma aparecer sem destaque no final do livro de Ciências, a possibilidade de se fazer a abordagem das questões relativas à hanseníase. E, principalmente, ressaltar nesta abordagem a promoção da saúde. Os indivíduos não se veem com doenças, porque não se identificam com elas. No entanto, identificam-se naturalmente com a promoção de saúde. Desta forma, utilizando-se material didático com ênfase na promoção de saúde, pode-se contribuir para a melhoria do ensino de ciência, particularmente sobre a doença hanseníase.

Não se trata simplesmente de oferecer palestras porque estas passam informações e divulgam. É importante, mas não é educação. Precisa muito mais. Para educar, as ideias, as crenças do público alvo devem ser conhecidas, para só depois desenvolver um trabalho de ensino calcado no conhecimento prévio daquela população. Com um material que seja adequado ao conhecimento que as pessoas já possuem e que não seja simplesmente um trabalho informativo, porque não repercute, mas deve ser formado numa perspectiva de respeito ao conhecimento da outra pessoa. Nesse sentido, nosso objetivo, nesta pesquisa, foi conhecer primeiramente o entendimento da comunidade escolar sobre a doença para, com isso, sensibilizar o corpo docente e discente para que eles introduzam o tema em sala de aula e discutam aspectos relativos à doença, a partir do desenvolvimento de trabalho de educação em saúde sobre a hanseníase nas escolas locais.

Há pouco respaldo para a implantação de 
ações educativas sobre a hanseníase nas escolas pesquisadas, o que representa um empecilho à luta pela promoção da saúde. No entanto, a Base Nacional Comum destina-se à formação geral do educando e a parte diversificada do currículo pode atender às características regionais e locais da sociedade, da cultura, da economia e do públicoalvo, conforme consta no Art. 26 da Lei de Diretrizes e Bases (LDB).

Assim, apesar de a maioria dos entrevistados na pesquisa reconhecer a falta de informações e saber da necessidade de adquirir conhecimento sobre a hanseníase, a inclusão do tema nas escolas é difícil, sendo a implementação de ações de promoção de saúde um desafio, principalmente o enfrentamento no contexto específico da hanseníase.

É imprescindível aos educadores detectar e discutir crendices e tabus e conversar a respeito com seus alunos, e, para isso, precisam de uma base teórica na abordagem das questões ligadas à hanseníase. "Ensinar exige a convicção de que a mudança é possível” (Paulo Freire).

A inclusão do tema hanseníase nas escolas pode ser feita através do desenvolvimento de um trabalho de educação efetivo voltado especialmente para a questão local. A população carece de informações e permanece o estigma, que é, provavelmente, consequência da dificuldade de enfrentamento do problema. Percebe-se com nitidez que os alunos aprendem em casa, com os mais velhos da família. Desta forma, tende-se a preservar os valores do mundo dos antepassados, inclusive a concepção de hanseníase como incurável. No entanto, com relação a esta enfermidade, mesmo os alunos com pais ou avós ex-portadores de hanseníase não pareciam demonstrar grande cabedal de conhecimento que os distinguisse radicalmente dos demais alunos.

Em termos de educação, não seria recomendável ignorar as necessidades da comunidade, como nos pareceu acontecer nesta região. Os conhecimentos podem ser mais facilmente aprendidos quando partem das preocupações que as pessoas já têm, ligadas a seus problemas cotidianos. Mais ainda, os conhecimentos científicos podem se tornar especialmente significativos quando são socialmente comprometidos. Conhecimentos selecionados a priori podem tornar-se esquecidos ou, simplesmente, não aplicados.
Esperamos que nossos dados possam contribuir para o desenvolvimento de estratégias metodológicas de ensino ligadas à promoção da saúde nas escolas do entorno do HETM e, quiçá, também possam influenciar no trabalho educacional no município a fim de que as populações locais possam enfrentar o problema desta enfermidade. "... A educação é um dos principais meios de realização de mudança social ou, pelo menos, um dos recursos de adaptação das pessoas a um mundo de mudança" (Brandão, 2004, p.78).

Na perspectiva de Bourdieu (1992), as estratégias mais adequadas são adotadas pelos grupos e incorporadas pelos sujeitos, integrando o seu habitus. Esse raciocínio, aplicado à educação, indica que, a partir de vivências de sucesso ou fracasso nas escolas, os grupos sociais buscam, inconscientemente, se adequar a estas oportunidades, ou seja, os indivíduos tendem a investir esforços conforme suas percepções de probabilidade de êxito. No caso dos educadores e educandos estudados, a aparente falta de motivação para fazer com que seja abordado o tema da hanseníase nas escolas pode estar assentada no habitus incorporado, na medida em que não sentem possibilidade de interferir no sentido de conseguir com que a escola possa tratar de uma questão central para sua comunidade. Ressaltamos, porém, que talvez este fato esteja relacionado às dificuldades das próprias pessoas que têm ou tiveram membros da família com hanseníase por receio de serem também estigmatizados.

Percebe-se que estas escolas não estão servindo como mediadoras de um conhecimento específico fundamental para a vida cotidiana na Colônia. Dessa forma, não estão contribuindo para a promoção da saúde, pois não enfrentam a hanseníase com informações e com uma formação cujo processo possa contribuir para evitar a recidiva e potencializar o esforço no sentido da prevenção, minorando a prevalência da doença. O Ensino em Biociências e Saúde pode proporcionar uma intervenção educativa voltada para a problemática local, visando à promoção de saúde a partir de um conjunto de práticas que, para serem efetivas, precisam se calcar em pesquisa como a que realizamos, cujos dados podem desvelar os caminhos para a melhoria da qualidade de vida em Itaboraí.

A educação é parte integrante de um 
processo de promoção da saúde que, se bem desenvolvido, pode oferecer subsídios para que os atores sociais possam enfrentar a problemática local de maneira eficaz. O que queremos dizer é que a escola deve se preocupar para além da elevação dos níveis de aprendizado formal, contribuindo para um verdadeiro processo de formação dos cidadãos para questões locais ou globais. Educadores bem preparados e comprometidos com as questões locais podem sensibilizar os gestores para compreender a realidade que os cerca e aplicar seus conhecimentos na localidade, a partir da aprendizagem dos seus alunos, apontando e enfrentando problemas de sua vida cotidiana, no que diz respeito à hanseníase. De acordo com (Léfèvre, 2004), a proposta atual é que a escola assuma o seu papel social, colaborando para que a saúde não seja vista como desdobramento do desempenho pessoal, mas do enfrentamento da comunidade.

Para a melhoria da qualidade de vida, neste caso associada à diminuição do estigma e prevalência da doença, a escola precisa formar parcerias, e uma relação de interação entre $o$ sistema escolar e a saúde seria muito bem-vinda. Muitas vozes discutem sobre a educação e algumas afirmam que a escola não é o único lugar onde a educação acontece e que, talvez, não seja o melhor. $\mathrm{O}$ ensino escolar não é a sua única prática e o professor não é o seu único praticante (Brandão, 2004).

\section{CONSIDERAÇÕES FINAIS}

O mundo não é. O mundo está sendo

(Paulo Freire).

O presente trabalho fez uma reflexão da dimensão crítico-reflexiva do processo ensinoaprendizagem de Ciências dos conhecimentos sobre hanseníase, a partir dos resultados de uma pesquisa que nos levou à reflexão sobre o ambiente escolar.

O significado da dimensão crítico-reflexiva tem a ver com as relações psicossociais dentro da escola. A maneira como o indivíduo se relaciona consigo mesmo e com o mundo social a que pertence como família, escola e a sociedade em geral. Desta forma, buscou-se contribuir para promover a reflexão sobre o conhecimento dispensado à hanseníase e também para diminuir preconceitos que são empecilhos ao desenvolvimento do processo ensino aprendizagem, para, com isso, integrar a problemática local da hanseníase ao comprometimento com a transformação da sociedade.

A educação foi, é, e será um processo complexo pelo fato de que o sujeito aprende o que é mais representativo para ele, ou melhor, aquilo que pode ser relacionado ao seu contexto. Assim, para aprender é necessário que o assunto a ser aprendido se relacione com as experiências vividas pelo aprendiz. Levando em conta essas considerações, precisa-se disponibilizar ao educando atividades que fomentem o pensamento e o agir a fim de enriquecer suas perspectivas de aplicação no cotidiano desta região, possibilitando a oportunidade de se fazer associações da aprendizagem com suas vivências.

Os dados coletados nesta pesquisa apontaram para a importância de se desenvolver um trabalho efetivo de educação em saúde nas escolas estudadas. E, para se fazer um trabalho nestas escolas, seria recomendável trabalhar com reconhecimento de campo, com base nos dados que coletamos por meio de diferentes fontes e estratégias que nos permitiram conhecer a cultura local. Também procuramos estabelecer um vínculo com a comunidade para ter acesso às suas concepções. Assim, acreditamos que este trabalho possa propiciar a criação de estratégias de intervenção educativa, seja através de materiais educativos ou de atividades pedagógicas que levem o aluno a refletir e discutir as questões ligadas à saúde, levando sempre em consideração os aspectos da cultura e da realidade locais.

As escolas têm um papel preponderante no desenvolvimento da capacidade de pesquisar e buscar informações que sejam relevantes para a realidade e que se coadunem com as exigências da sociedade. De maneira geral, estão comprometidas com um currículo universal contendo temas que são indicados para serem tratados naquelas séries em todo o território nacional, mas uma parte do currículo pode ser dedicado a questões regionais, abordando temas relevantes para a cultura local. Os próprios Parâmetros Curriculares Nacionais (PCN) de Ciências Naturais trazem, em seu bojo, orientações que apontam para a valorização do ensino das questões relacionadas à cultura local, que devem ser respeitadas tanto quanto às referentes ao currículo universal.

Ao incorporar ao currículo questões do seu 
cotidiano, abordando conteúdos que são interessantes e importantes em um processo de ensino-aprendizagem, a comunidade escolar terá mais oportunidade de se apropriar dos saberes científicos ligados à saúde. Utilizando-se do conhecimento sobre os aspectos relacionados à enfermidade hanseníase como guia para repensar a inclusão, para nortear ações que garantam a diminuição das desigualdades sociais, das injustiças e do sofrimento.

Esperamos que através do trabalho coletivo, a escola busque favorecer novos comportamentos de solidariedade valor humano muito importante. Assim, conduzindo educadores e educandos a ter maior conscientização de sua própria atitude perante o portador de hanseníase, contribui-se para minimizar a discriminação, inventando novas maneiras de se lidar com as diferenças, reinventando posturas e didáticas e enfrentando a distância entre o professor e o aluno. Amplia-se e promove-se, dessa forma, o debate e a reflexão entre todos, inclusive aqueles estudantes vitimados da doença, que terão oportunidade de participar da realização de uma escola mais humana, que se transforme sempre para melhor, cumprindo seu papel social de conduzir a uma vida mais saudável e feliz.

Dessa maneira, procura-se partir da escola que temos para considerar a escola que queremos, dos educadores que somos para os que desejamos ser, dos alunos como se mostram hoje e como eles poderão vir a ser, indivíduos conscientes de sua alta qualidade como seres plenamente desenvolvidos. E podemos contribuir para isso melhorando as relações humanas, na escola, principalmente, nas questões que envolvem estigma, em geral, tais como deficiências visuais, auditivas, físicas e mentais, além de doenças contagiosas, tal como a hanseníase.

Podemos concluir pela necessidade de ampliar o processo de construção do conhecimento, mediante reflexões a respeito de saúde e promoção de saúde no que se refere à hanseníase, pois, a construção de uma sociedade mais justa e solidária exige a participação das pessoas que compõem a escola, especialmente educadores e educandos.
BRANDÃO, C. R. O que é educação. São Paulo: Brasiliense, 2004

BRASIL. Ministério da Educação e do Desporto. Secretaria de Educação. PARÂMETROS CURRICULARES NACIONAIS. PCN'S de Ciências Naturais, Brasília: Ministério da Educação e do Desporto - MEC, 1998.

.Ministério da Educação. Lei de Diretrizes e Bases da Educação Nacional $L D B$. Fundo de Valorização do Magistério $2^{a}$ Edição, 1997

LEFÈVRE, Fernando e LEFÈVRE, Ana Maria. $A$ negação da negação, Rio de Janeiro: Vieira \& Lent, 2004

GOFFMAN, Erving. Estigma Notas sobre a Manipulação da Identidade Deteriorada. Rio de Janeiro: Zahar, 1975.

LÜDKE, M. e ANDRÉ, M. Pesquisa em Educação: Abordagens Qualitativas. São Paulo: E. P.U, 1986.

MINAYO, M.C., (org.) Pesquisa social: teoria, método e criatividade. Petrópolis, RJ: Vozes, 1994

\section{REFERÊNCIAS}

BOURDIEU, P. O poder simbólico. Rio de Janeiro: Bertrand Brasil, 2004. 